\title{
Control of degassing systems
}

\author{
Leonid Novikov ${ }^{1, *}$ \\ ${ }^{1}$ Institute of Geotechnical Mechanics named by N. Poljakov of National Academy of Sciences of \\ Ukraine, 49005, Dnipro, Simferopolska Str., 2a, Ukraine
}

\begin{abstract}
The methods and means of control for gas pipelines, as well as signs of liquid accumulation are present. Dependencies for determining the volume flow of gas mixture and the absolute equivalent roughness for internal surface of degassing pipeline is given. The graph of changes in local pressure losses of the gas mixture in the place of fluid accumulation is given. Analysis of the results of experimental studies of the aerodynamic drag of pipeline section in the place of liquid accumulation is out. Results of measurements for methane concentration in ventilation working out when stopping degassing are present.
\end{abstract}

\section{Introduction}

Operation of the mine degassing system involves automatic control and management of degassing. The main tasks of automatic regulation and control include [1]:

1. Automatic of vacuum pumps shutdown.

2. Control of gas mixture parameters in degassing wells, in precinct and main pipelines, as well as in suction nozzles of vacuum pumps.

3. Automatic shut-off of main and backup vacuum pumps.

4. Discharge of gas into the atmosphere and cessation of gas supply to the consumer.

The following parameters are controlled in degassing pipeline: gas concentration and dust content; gas mixture humidity; gas mixture pressure; gas mixture temperature; gas mixture velocity.

The efficiency of degassing systems depends on the mining and geological conditions, technical condition of the pipelines. With the complexity a topology of degassing network, it is necessary to increase the number and power of vacuum pumps. This is necessary to ensure the effectiveness of degassing.

Violation of degassing processes because of the influence of technological and mining factors leads to a decrease in the volume of methane extraction. In this case, there is an increase in the concentration of methane in the mine workings. A malfunction of the degassing pipelines leads to a decrease in the concentration of methane in the gas mixture to dangerous values.

Monitoring of degassing processes is necessary to reduce the probability of accidents at coal mines during the extraction and transportation of methane to the consumer. This question is most relevant when mining in difficult geological conditions in mines that are dangerous for gas and dust.

*Corresponding author: lnov710@gmail.com 


\section{Methods}

To monitor the status of degassing pipelines are used [2]: vortex gas flow meter IRBIS P30; velocity meter of gas StRP ("Warholt and Germeler"); sensors carbon dioxide and methane ("Industrialelectronic Woelke GmbH Trolex and Society"); analyzers for gas GDXL, GD200; control system and measurement Politron ("Dragor"). RIKEN Keiki (Japan) develops gas analysis systems and optical devices. Fiber-optic sensors are also of interest. These sensors can be combined into control systems and allow to determine gas parameters with high accuracy.

Table 1 presents the methods of pipeline diagnostics.

Table 1. Methods for diagnostics of pipelines during transportation of gases and liquids.

\begin{tabular}{|c|c|c|}
\hline Title & Functions & Disadvantages \\
\hline Cost comparison & $\begin{array}{c}\text { a flow rate comparison at } \\
\text { the beginning and end of } \\
\text { pipeline }\end{array}$ & $\begin{array}{l}\text { the impossibility to detect } \\
\text { damage to the pipeline }\end{array}$ \\
\hline $\begin{array}{l}\text { Pressure } \\
\text { monitoring } \\
\text { with fixed or } \\
\text { removable } \\
\text { installation } \\
\end{array}$ & $\begin{array}{l}\text { comparison of pressures at } \\
\text { pumping and discharge } \\
\text { stations with the values for } \\
\text { a given performance }\end{array}$ & $\begin{array}{c}\text { not applicable for pipelines with } \\
\text { variable diameters and when } \\
\text { changing the density of the } \\
\text { medium }\end{array}$ \\
\hline Linear balance & $\begin{array}{l}\text { comparison of flow rate } \\
\text { losses with the reference } \\
\text { pipeline }\end{array}$ & $\begin{array}{l}\text { not used to identify pipeline } \\
\text { damage sites }\end{array}$ \\
\hline $\begin{array}{c}\text { Comparison } \\
\text { of change flow rate }\end{array}$ & $\begin{array}{c}\text { an instantaneous change in } \\
\text { flow rate is determined } \\
\text { when the pipeline is } \\
\text { damaged }\end{array}$ & $\begin{array}{l}\text { the reaction of automatic is not } \\
\text { taken into account when changing } \\
\text { the parameters of the energy } \\
\text { carrier, pipeline damage is not } \\
\text { detected }\end{array}$ \\
\hline Acoustic diagnosis & $\begin{array}{c}\text { analysis of acoustic } \\
\text { vibrations in the places of } \\
\text { leakage }\end{array}$ & $\begin{array}{l}\text { not used for pipelines with } \\
\text { diameter more than } 0.5 \mathrm{~m}\end{array}$ \\
\hline
\end{tabular}

According to Table 1, the universal method of control is the method of acoustic diagnostics (spectral, amplitude, correlation).

This method has a large range of measurements and is resistant to external influences. The method is applicable to control the tightness of pipelines and the flow rate of gas mixture.

Table 2 summarizes the classification of controls by degassing systems.

Table 2. Generalized classification of the regulators degassing systems.

\begin{tabular}{|c|c|c|c|}
\hline Absolute pressure & Gas concentration & Consumption & Temperature \\
\hline $\begin{array}{c}\text { pressure gauges; } \\
\text { vacuum gauges; } \\
\text { pressure sensors }\end{array}$ & $\begin{array}{c}\text { interferometers; } \\
\text { gas analyzers; } \\
\text { concentration sensors }\end{array}$ & $\begin{array}{c}\text { differential } \\
\text { pressure gauge; } \\
\text { speed and flow meters }\end{array}$ & $\begin{array}{c}\text { themometers; } \\
\text { temperature } \\
\text { sensors }\end{array}$ \\
\hline
\end{tabular}

Control devices shown in Table 2, are divided into stationary and portable. The 
advantage of portable devices is the ability to control the gas-dynamic parameters at any point of the degassing network.

The parameters of gas mixture in degassing pipelines [3] are control at the measuring diaphragms and through the hole drilled in the walls of the pipeline [4]. The diaphragms are mounts before and after the pipeline turns. The diameter is measuring hole varies from 6 to $8 \mathrm{~mm}$.

It should is considered into account that control devices of precinct and main pipelines are not always installed in the right places and in the required quantity. Therefore, there are problems in identifying damage to pipelines and accumulations of liquid (or dust).

In Figure 1 the scheme of the measuring section of degassing pipeline with the accumulation of liquid is presented.

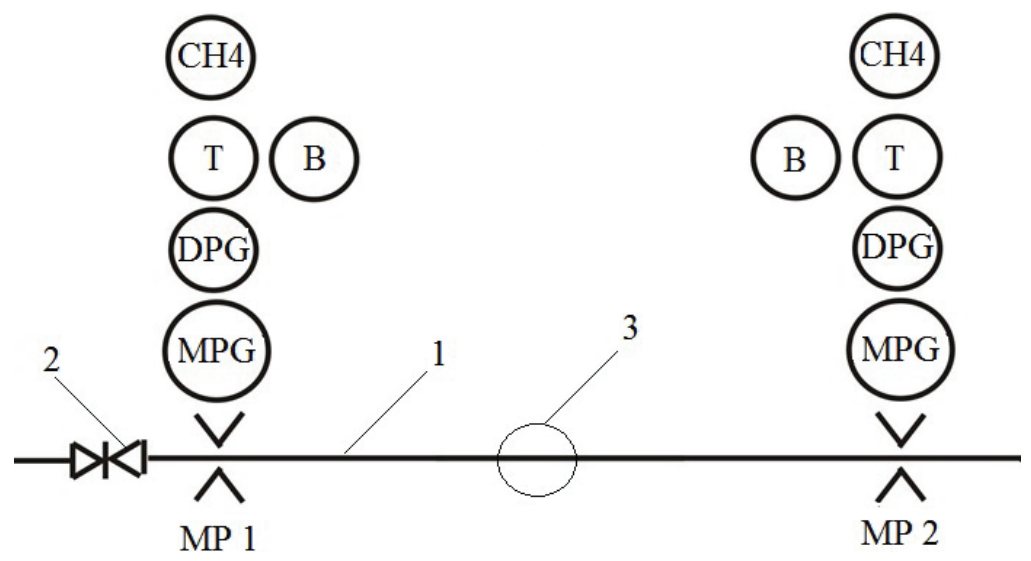

Fig. 1. Control of degassing pipeline section: 1 - degassing pipeline; 2 - control valve; 3 - liquid accumulation; MP 1, MP 2 - measurement points; MPG - micro pressure gauge; DPG - differential pressure gauge; $\mathrm{T}$ - thermometer; $\mathrm{B}$ - barometer; $\mathrm{CH} 4$ - interferometer.

When measuring on the diaphragm, a methane concentration and pressure difference are determined. According to the obtained pressure drop is the flow rate of the gas mixture.

When determining the flow rate of the gas mixture through the hole in the wall of the pipeline, speed meters are used.

The flow rate of gas mixture is determined by the formula:

$$
Q=U k S \frac{p T_{0}}{p_{0} T},
$$

where $k$ is correction coefficient on pipeline diameter; $S$ is cross-sectional area of the pipeline, $\mathrm{m}^{2} ; U$ is speed of the gas mixture, $\mathrm{m} / \mathrm{s} ; p$ is absolute pressure of the gas mixture in the pipeline, $\mathrm{Pa} ; p_{0}$ is pressure of the air at normal conditions, $\mathrm{Pa} ; T$ is temperature of the gas mixture in the pipeline, $\mathrm{K} ; T_{0}$ is air temperature under normal conditions, $\mathrm{K}$.

The value of the absolute pressure loss of the gas mixture at the pipeline section (Fig. 1) determined by the formula:

$$
\Delta p=\frac{p_{1}{ }^{2}-p_{2}{ }^{2}}{2 \bar{p}},
$$

where $p_{1}$ is absolute pressure of the gas mixture in the first measurement point, $\mathrm{Pa} ; p_{2}$ is absolute pressure of the gas mixture at the second measurement point, $\mathrm{Pa} ; \bar{p}$ is average absolute pressure of gas mixture, $\mathrm{Pa}$. 
The loses of absolute pressure in the place of accumulation of liquid is determined by the formula:

$$
\Delta p_{z}=\Delta p_{\text {clean }}-\Delta p_{\text {foul }},
$$

where $\Delta p_{\text {clean }}, \Delta p_{\text {foul }}$ are loss of absolute pressure, respectively, unpolluted section of the pipeline and with the accumulation of liquid, $\mathrm{Pa}$.

In the place of accumulation of liquid there is a narrowing and expansion of the flow section of the pipeline. In the expansion zone, pressure losses reach a maximum.

The coefficient of local resistance in this area can be determined by analogy with a cylindrical diffuser:

$$
\zeta_{e x t}=3.2\left[\operatorname{tg}^{1.25}\left(\frac{\beta_{e x t}}{2}\right)\right]\left(1-\frac{S_{\min }}{S}\right)^{2},
$$

where $\beta_{\text {ext }}$ - angle of expansion, deg; $S_{\min }=f(h)$ - minimum cross-sectional area of the pipeline in the place of liquid accumulation, $\mathrm{m}^{2} ; h$ - liquid level, $\mathrm{m}$.

\section{Results and discussion}

In Figure 2 the dependence of the pressure loss of gas mixture on its instantaneous flow rate in the place of liquid accumulation is presented.

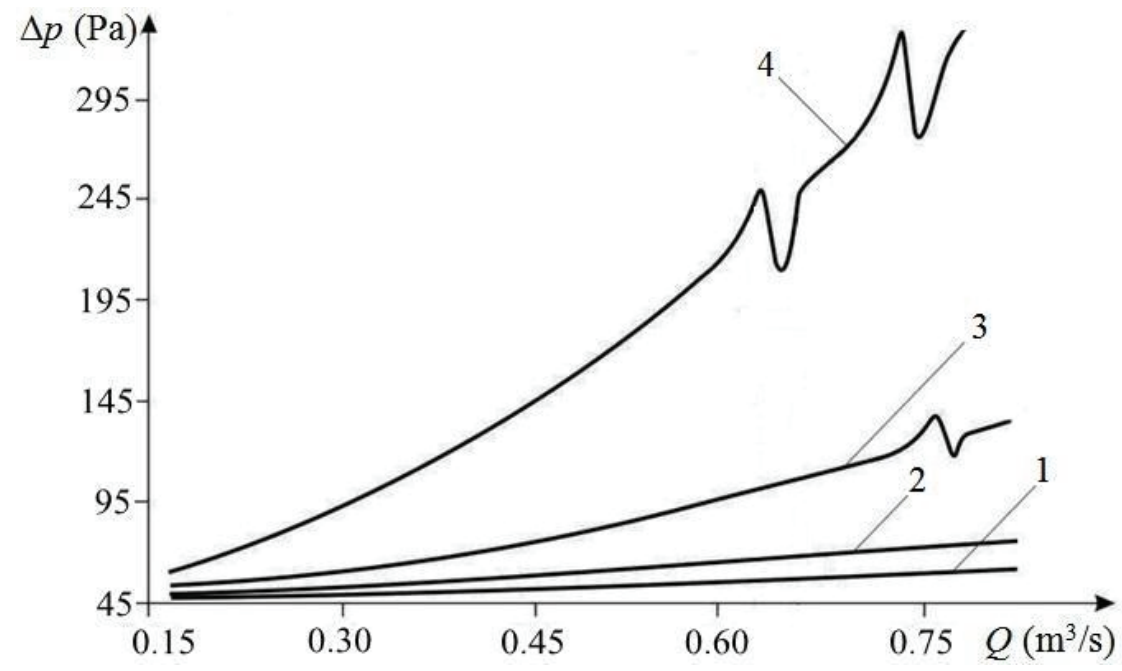

Fig. 2. Dependence of pressure losses of gas mixture on its flow rate at different levels of liquid in the place of accumulation: $1-h=0.1 d ; 2-h=0.2 d ; 3-h=0.5 d ; 4-h=0.75 d$.

It follows from Figure 2 that an increase in the flow rate of gas mixture leads to an increase in intensity for liquid disturbances. At $h \geq 0.5 d$, pronounced pressure loses oscillations are observed.

This is due to the increase in the intensity of interfacial interactions and periodic overlap of the cross-section of the pipeline with liquid.

The following features accompany the formation of liquid accumulations in pipelines: pronounced fluctuations in the flow rate of the gas mixture, the magnitude of the discharge and the absolute equivalent roughness of the inner surface for pipeline. In particular, the absolute equivalent roughness can reach abnormal values. 
The influence of liquid accumulations leads to a decrease in the efficiency of degassing and an increase in the concentration of methane in mine workings. At the same time, the methane concentration is additionally increased when the vacuum pumps are switched off for technical measures to clean the pipelines and during the reconstruction of the degassing network.

To assess the effect of degassing on the gas situation in the mine workings, experimental studies of the effect of degassing time on the concentration of methane in the ventilation flow were carried out.

The studies were carried out at the Zasiadko mine from 2003 to 2004, where the methane concentration in the ventilation workings (16th Western lava of the $m_{3}$ layer) was measured when degassing was switched off $[5,6]$ (Table. 3 ).

Table 3. Results of measuring the concentration of methane in the ventilation output.

\begin{tabular}{|c|c|c|c|}
\hline $\begin{array}{l}\text { Time } \\
t, \text { min }\end{array}$ & $\begin{array}{c}\text { Methane concentration } \\
\qquad, \%\end{array}$ & $\begin{array}{l}\text { Time } \\
t, \text { min }\end{array}$ & $\begin{array}{c}\text { Methane concentration } \\
\qquad c, \%\end{array}$ \\
\hline \multicolumn{2}{|c|}{ Shutdown degassing for $20 \mathrm{~min}$} & \multicolumn{2}{|c|}{ Shutdown degassing for $60 \mathrm{~min}$} \\
\hline 0 & 0.40 & 0 & 0.40 \\
\hline 10 & 1.00 & 10 & 0.80 \\
\hline 12 & 1.20 & 12 & 1.15 \\
\hline 20 & 2.40 & 20 & 2.45 \\
\hline \multicolumn{2}{|c|}{ Large diameter pipeline start-up } & 25 & 2.50 \\
\hline 20 & 2.40 & 30 & \multirow{2}{*}{2.80} \\
\hline 25 & 1.75 & 40 & \\
\hline \multicolumn{2}{|c|}{ Inclusion of degassing wells } & \multicolumn{2}{|c|}{ Inclusion of degassing } \\
\hline 35 & 0.80 & 60 & 2.80 \\
\hline 40 & 0.50 & 70 & 1.30 \\
\hline
\end{tabular}

When degassing underground wells (connected to the degassing pipeline) and a large diameter pipeline $(d=603 \mathrm{~mm})$ were used, through which a gas mixture was taken from the worked-out space.

From the analysis of Table 3 it follows that the shutdown and start of degassing leads to a change in concentration of methane in development only after some time. After that, there is an increase (or decrease) in the concentration of methane.

At $t>10$ minutes, methane concentration exceeds the permissible value $(1 \%)$. With increasing time shutdown degassing, methane concentration reaches a constant maximum of $2.8 \%$.

The results are approximated by functions of the form:

$$
c(t)=a \cdot e^{b \cdot t}
$$

where $a, b$ are numerical coefficients.

Experimental studies conducted at the Zasiadko mine [7] showed that the share of degassing in the gas balance could reach $70-80 \%$. There is a technical possibility to increase methane production by degassing wells in 1.5-2 times.

This indicates the feasibility of improving the technological schemes of degassing wells. 


\section{Conclusions}

The conducted research allowed drawing conclusions:

1. For diagnostics of mine pipelines, it is recommend using acoustic devices and fiberoptic sensors.

2. Accumulations of liquid lead to fluctuations of gas-dynamic parameters in degassing pipelines. In particular, at the initial reduction of the cross-section of the pipeline by $50 \%$ or more, pronounced fluctuations in the pressure losses of the gas mixture and periodic changes in the flow capacity are observed.

3. Disable the degassing leads to an increase of concentration methane in development up to constant maximum of 30 minutes.

\section{References}

1. Novikov, L.A., Bokiy, B.V. (2012). On control and automation of mine degasification systems, Geotechnical Mechanics, (98), 64-69

2. Hivrin, M.E., Kubrin, S.S., Sobenevskiy, A.G. (2012). Monitoring the parameters of the methane-air mixture in the degassing pipeline of a coal mine, Gornyy informatsionno-analiticheskiy byulleten, (2), 80-88

3. Novikov, L.A. (2015). Gas dynamics flooded areas degassing pipeline and methods of calculation of parameters, Geotechnical Mechanics, (120), 234-243

4. Samarin, O.D. (2016). Postroenie universalnoy zavisimosti dlya poter davleniya $v$ truboprovodah, Santehnika, otoplenie, konditsionirovanie, (1), 24-25

5. Bunko, T.V., Novikov, L.A., Dudnik, M.N., Miroshnichenko, V.V. (2018). Influence of liquid accumulations on gas-dynamic characteristics of degassing pipeline, The scientific method, 1, (17), 50-55

6. Bulat, A.F., Bun'ko, T.V., Yashchenko, I.A., Shishov M.V., Miroshnichenko, V.V., Alabev, V.R., Bokiy, A.B., Novikov, L.A., Dudnik, M.N., Kokoulin, I.E. (2018). Sovershenstvovaniye funktsionirovaniya ugol'nykh shakht: ventilyatsiya, konditsionirovaniye, degazatsiya, ekologiya. Dnepr: Zhurfond

7. Bokiy, A.B. (2013). Estimation of environment-friendly operation of the working areas in the coal mines, Geotechnical Mechanics, (112), 196-201 